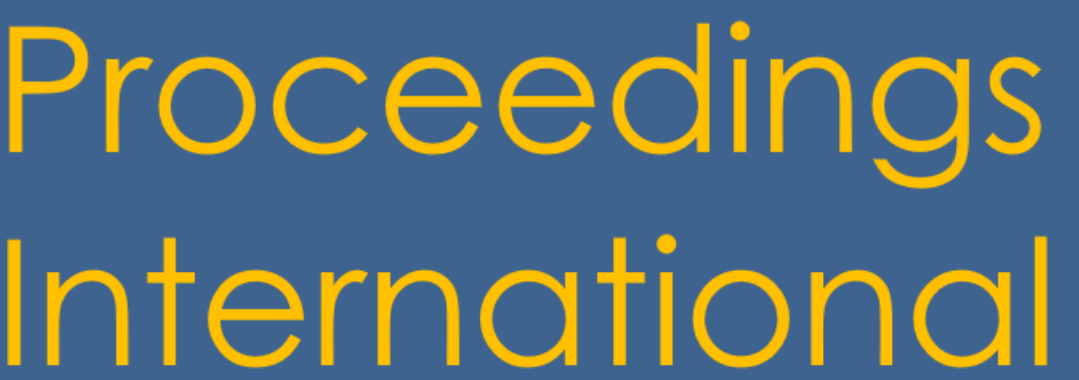

Volume 1, Issue 1, Pages 0008-0010 2019

Proceedings, Abstract

\title{
Atomic resolution structural and analytical characterization of layered precipitates in special alloys for high-temperature applications
}

\author{
C. Ghica ${ }^{1}$, C. Solís ${ }^{2}$, J. Munke ${ }^{2}$, A. Stark ${ }^{3}$, B. Gehrmann ${ }^{4}$, M. Bergner ${ }^{5}$, J. Rösler ${ }^{5}$, R. Gilles ${ }^{2}$ \\ National Institute of Materials Physics, 077125 Măgurele, Romania \\ 2 Heinz Maier-Leibnitz Zentrum (MLZ), TU München, 85748 Garching, Germany \\ 3 Institute of Materials Research, Helmholtz-Zentrum Geesthacht, 21502 Geesthacht, Germany \\ 4 VDM Metals International GmbH, 58762 Altena, Germany \\ 5 Institut für Werkstoffe, Technische Universität Braunschweig, 38106 Braunschweig, Germany \\ * Correspondence: cghica@infim.ro; Scopus ID: 6603955468
}

Ni-base superalloys (e.g. Alloy 718) are largely used nowadays for manufacturing metallic components like gas turbine engine disc components for land-based power generation and aircraft propulsion to be exploited at high temperatures, due to their excellent mechanical properties and resistance to corrosive or oxidizing environments. The VDM 780 Premium alloy has been recently developed [1] in order to push even further the temperature limits of the widely used Alloy 718. This newly developed Ni-base superalloy is based on the $\gamma$ matrix (Ni-based cubic Fm-3m structure) and $\gamma^{\prime}$ hardening precipitates $\left(\mathrm{Ni}_{3} \mathrm{Al}\right.$-based cubic $\mathrm{Pm}-3 \mathrm{~m}$ structure). The amount of the various crystal phases, the size and morphology of the different precipitates depend on the particularities of the applied heat treatments. The crystal phases obtained during the thermal treatment at high-temperature determine the grain size evolution and the mechanical properties of the alloy operating at high temperature. This HRTEM study brings a decisive contribution in understanding the structure of the high-temperature precipitates formed in the newly developed alloy VDM 780 Premium. For this purpose, we combined various techniques of analytical electron microscopy, including electron diffraction, atomic-resolution imaging, chemical characterization by EDS and EELS, elemental mapping by STEM-EDS ans STEM-EELS as well as structural modelling. Our results corroborated from SAED patterns, HRTEM imaging and local FFT diagrams have revealed that the high-temperature precipitates in the alloy VDM 780 Premium exhibit a layered structure consisting of alternating $\delta$ and $\eta$ phases in the crystallographic orientation relationship $[010]_{\eta}\left\|[100]_{\delta},(001)_{\eta}\right\|(010)_{\delta},(100)_{\eta} \|(001)_{\delta}$.

Keywords: atomic resolution, alloys, Ni3 Al-based cubic Pm-3m structure, SAED, HRTEM.

\section{Funding}

PROCEEDINGS INTERNATIONAL | https://conferenceproceedings.international | 8

Cite This Work: Ghica, C.; Solís, C.; Munke, J.; Stark, A.; Gehrmann, B.; Bergner, M.; Rösler, J.; Gilles, R. Atomic resolution structural and analytical characterization of layered precipitates in special alloys for high-temperature applications. Proceedings Int 2019, 1, 0008-0010.

https://doi.org/10.33263/Proceedings 11.00080010 
C. Ghica, C. Solís, J. Munke, A. Stark, B. Gehrmann, M. Bergner, J. Rösler, R. Gilles

Not applicable.

\section{Acknowledgments}

CG acknowledges the financial support from Romanian Ministry of Research and Innovation in the frame of the PCE 134/2017 and Core Program PN19-03.

\section{Conflicts of Interest}

The authors declare no conflict of interest.
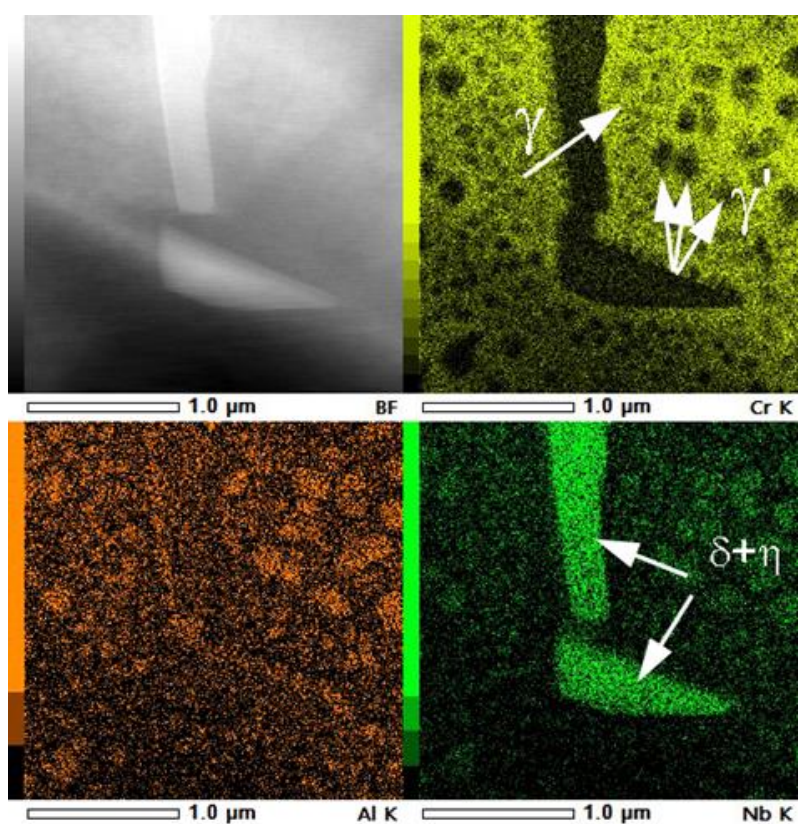

Figure 1. Low-magnification STEM-HAADF image and STEM-EDS elemental maps of $\mathrm{Cr}, \mathrm{Al}$ and $\mathrm{Nb}$ evidencing the presence of different precipitates having different chemical compositions within alloy VDM 780.

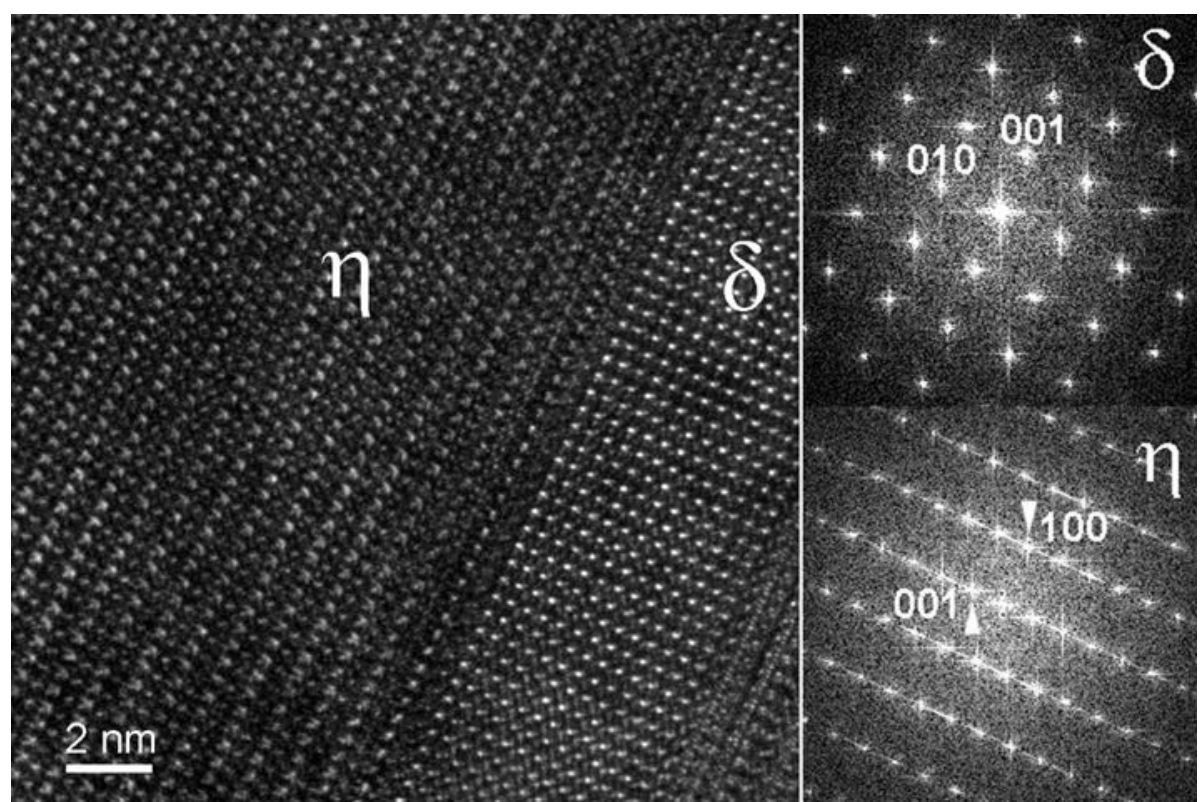

Figure 2. HRTEM image showing different atomic structures inside two adjacent bands forming a typical plateshaped precipitate within alloy VDM 780; (d) FFT diagrams corresponding to the two adjacent bands of $\eta$-phase and $\delta$-phase.

\section{References}


1. Fedorova, T.; Rösler, J.; Gehrmann, B.; Klöwer, J. 8th International Symposium on Superalloy 718 and Derivatives. Ott, E.; Banik, A.; Andersson, J.; Dempster,
I.; Gabb, T.; Groh, J.; Heck, K.; Helmink, R.; Liu, X.; Wusatowska-Sarnek, A. (eds.), TMS 2014; pp. 587-599.

(C) 2019 by the authors. This article is an open access article distributed under the terms and conditions of the Creative Commons Attribution (CC BY) license (http://creativecommons.org/licenses/by/4.0/). 